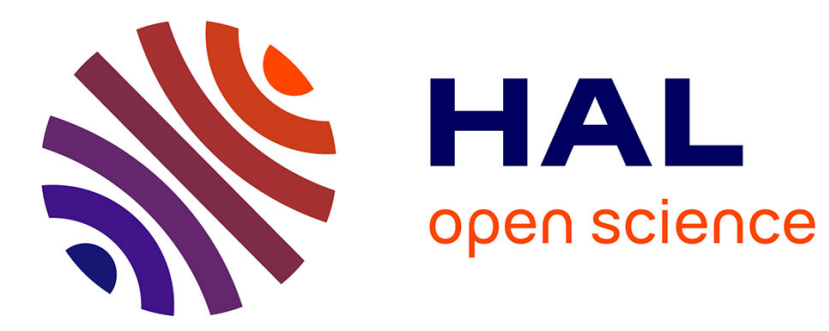

\title{
Medication errors at hospital admission and discharge in Type 1 and 2 diabetes
}

\author{
Cyril Breuker, V. Macioce, T. Mura, Y. Audurier, C. Boegner, A. Jalabert, \\ M. Villiet, A. Castet-Nicolas, Antoine Avignon, A. Sultan
}

\section{- To cite this version:}

Cyril Breuker, V. Macioce, T. Mura, Y. Audurier, C. Boegner, et al.. Medication errors at hospital admission and discharge in Type 1 and 2 diabetes. Diabetic Medicine, 2017, 34 (12), pp.1742-1746. 10.1111/dme.13531 . hal-01743298

\section{HAL Id: hal-01743298 https://hal.science/hal-01743298}

Submitted on 13 Dec 2019

HAL is a multi-disciplinary open access archive for the deposit and dissemination of scientific research documents, whether they are published or not. The documents may come from teaching and research institutions in France or abroad, or from public or private research centers.
L'archive ouverte pluridisciplinaire HAL, est destinée au dépôt et à la diffusion de documents scientifiques de niveau recherche, publiés ou non, émanant des établissements d'enseignement et de recherche français ou étrangers, des laboratoires publics ou privés. 


\title{
Medication errors at hospital admission and discharge in Type 1 and 2 diabetes
}

\author{
C. Breuker ${ }^{1,2}$ D, V. Macioce ${ }^{3}$, T. Mura ${ }^{3}$, Y. Audurier ${ }^{1}$, C. Boegner $^{4}$, A. Jalabert ${ }^{1}$, M. Villiet ${ }^{1}$, \\ A. Castet-Nicolas ${ }^{1,5}$, A. Avignon ${ }^{2,4}$ and A. Sultan ${ }^{2,4}$ (iD \\ ${ }^{1}$ Clinical Pharmacy Department, University Hospital of Montpellier, ${ }^{2}$ PhyMedExp, University of Montpellier, INSERM U1046, CNRS, UMR 9214, ${ }^{3}$ Clinical Research \\ and Epidemiology Unit, ${ }^{4}$ Endocrinology-Diabetology-Nutrition Department, University Hospital of Montpellier and ${ }^{5}$ IRCM, University of Montpellier, INSERM \\ U1194, France
}

\section{Abstract}

Aims To assess the prevalence and characteristics of medication errors at hospital admission and discharge in people with Type 1 and Type 2 diabetes, and identify potential risk factors for these errors.

Methods This prospective observational study included all people with Type $1(n=163)$ and Type 2 diabetes $(n=508)$ admitted to the Diabetology-Department of the University Hospital of Montpellier, France, between 2013 and 2015. Pharmacists conducted medication reconciliation within $24 \mathrm{~h}$ of admission and at hospital discharge. Medication history collected from different sources (patient/family interviews, prescriptions/medical records, contact with community pharmacies/general practitioners/nurses) was compared with admission and discharge prescriptions to detect unintentional discrepancies in medication indicating involuntary medication changes. Medication errors were defined as unintentional medication discrepancies corrected by physicians. Risk factors for medication errors and serious errors (i.e. errors that may cause harm) were assessed using logistic regression.

Results A total of 322 medication errors were identified and were mainly omissions. Prevalence of medication errors in Type 1 and Type 2 diabetes was $21.5 \%$ and $22.2 \%$ respectively at admission, and $9.0 \%$ and $12.2 \%$ at discharge. After adjusting for age and number of treatments, people with Type 1 diabetes had nearly a twofold higher odds of having medication errors (odds ratio (OR) 1.72, 95\% confidence interval (CI) 1.02-2.94) and serious errors (OR 2.17, 95\% CI 1.02-4.76) at admission compared with those with Type 2 diabetes.

Conclusions Medication reconciliation identified medication errors in one third of individuals. Clinical pharmacists should focus on poly-medicated individuals, but also on other high-risk people, for example, those with Type 1 diabetes.

\section{Introduction}

Medication errors are very common in hospitals and may have important clinical and economic consequences [1]. To decrease the error rate and improve medication safety, several institutions have recommended medication reconciliation at all transition points: admission, transfer and discharge [1-3]. Medication reconciliation consists of drawing up a complete and correct list of an individual's current medications and comparing it with prescriptions at the different steps of hospitalization in order to identify and document discrepancies [4]. A recent meta-analysis showed that medication reconciliation programmes run by pharmacists are effective in reducing medication discrepancies [5].

Correspondence to: Cyril Breuker. E-mail: c-breuker@chu-montpellier.fr
However, studies evaluating the efficacy of such programmes are very heterogeneous in terms of methodology, populations and definitions of outcome measures. Whereas most studies have included people admitted to hospital for various reasons [6-10], the few studies focusing on specific populations concerned those with heart disease $[11,12]$ or the elderly $[13,14]$. As the number of medications is often a risk factor for medication errors $[6,12]$, it is likely that people with chronic diseases like diabetes are at increased risk of these errors [15]. Indeed, we have already demonstrated that people with diabetes do have a higher risk of medication error than those without diabetes [15]. Further, because individuals with Type 1 and Type 2 diabetes have different clinical characteristics, it seems important to compare prescribing errors between these two groups. Our study assessed the prevalence and characteristics of these errors 


\section{What's new?}

- Nearly one third of people with diabetes have errors on their medication prescription at hospital admission and/ or discharge.

- The risk of medication errors and serious medication errors at hospital admission is higher in people with Type 1 than those with Type 2 diabetes.

- Our findings should heighten the awareness of diabetes care teams regarding the risk of medication errors in people with diabetes, especially in those with Type 1 diabetes.

detected at hospital admission and discharge according to the type of diabetes. This article is a complementary analysis of our previously published study [15].

\section{Participants and methods}

\section{Study design and population}

This study was carried out in the Diabetology Department of the University Hospital of Montpellier, France and has been described previously [15]. All adults with Type 1 or Type 2 diabetes admitted to this department between November 2013 and May 2015 were prospectively included and followed until hospital discharge.

\section{Medication reconciliation at admission and discharge}

At admission, the pharmacy team, including a senior pharmacist, one resident and two pharmacy students, undertook the medication reconciliation process within $24 \mathrm{~h}$ of admission. This is standard procedure in the Diabetology Department of the University Hospital of Montpellier, and follows a validated protocol, as described previously [15]. Pharmacists and physicians discussed each discrepancy between the medication history and the hospitalization prescription to determine whether it was intentional or unintentional. Unintentional medication discrepancies corrected by the physician were considered medication errors. The same procedure was followed at discharge before participants left the hospital.

\section{Data collection}

Demographic, clinical and biological data were collected prospectively. For each medication, we documented the name, dosage, dosage forms and administration frequency. For each medication error, we documented the drug class and the potential clinical impact for the participant. The potential clinical impact (very serious, serious, moderate and minor) was determined by the consensus of an expert panel made up of two pharmacists and two senior clinicians from the department [15]. For $9(5.5 \%)$ and $24(4.7 \%)$ people with, respectively, Type 1 and Type 2 diabetes the discharge prescriptions could not be analysed because discharge took place at night or at the weekend.

\section{Statistical analysis}

Quantitative variables were compared using the MannWhiney $U$-test. For categorical variables, comparisons were made using chi-squared or Fisher's exact tests. Data are presented as median and interquartile range (IQR) or $n(\%)$. The relationship between the type of diabetes and the risk of medication errors (or serious medication errors) was analysed using logistic regression. We first built a crude model, followed by a model adjusted for the number of lines of the prescription at admission or discharge. We finally added age in a third and final multivariate logistic model.

Statistical analyses were performed at the conventional two-tailed $\alpha$ level of 0.05 using SAS version 9.1 (SAS Institute, Cary, NC, USA).

\section{Results}

\section{Participant characteristics}

We included 671 people; 163 (24.3\%) with Type 1 diabetes and $508(75.7 \%)$ with Type 2 diabetes. The median (IQR) age of those with Type 1 and 2 diabetes was $42(31-58)$ and 63 (55-72) years respectively. People with Type 1 diabetes were more often admitted for management of diabetes at night or at the weekend, and more often via the emergency department. Participant characteristics on admission are presented in Table 1.

\section{Medication errors}

Overall, 197 people $(29.4 \%)$ had at least one medication error detected at admission and/or discharge (Table 1). The percentage of medication errors per treatment was higher in people with Type 1 diabetes than in those Type 2 diabetes only at admission: median (IQR) $16.7 \%(12.5 \%-$ $26.8 \%)$ vs $12.5 \%(9.0 \%-20 \%)(P=0.02)$. At admission, people with Type 2 diabetes had significantly more medication errors involving cardiovascular medication than those participants with Type 1 diabetes $(38.6 \%$ vs $19.3 \%$, $P<0.01)$. A trend toward higher medication errors involving drugs used for diabetes management was observed on admission in people with Type 1 compared with Type 2 diabetes ( $17.9 \%$ vs $9.3 \%, P=0.08)$. In both groups, at both admission and discharge, omissions were the first cause of medication errors $(59.6 \%)$. At admission, added medications were more frequent in those with Type 1 diabetes $(12.5 \%$ vs $1.2 \%, P<0.001)$, whereas wrong administration frequencies or doses were found more often 


\begin{tabular}{|c|c|c|c|}
\hline & $\begin{array}{l}\text { Type } 1 \text { diabetes } \\
(n=163)\end{array}$ & $\begin{array}{l}\text { Type } 2 \text { diabetes } \\
(n=508)\end{array}$ & $P$ \\
\hline Age, years* & $42(31-58)$ & $63(55-72)$ & $<0.001$ \\
\hline Sex, male & $97(59.5)$ & $307(60.4)$ & 0.83 \\
\hline $\mathrm{BMI} \geq 30 \mathrm{~kg} / \mathrm{m}^{2}$ & $26(15.9)$ & $288(56.7)$ & $<0.001$ \\
\hline \multicolumn{4}{|l|}{ Reason for admission } \\
\hline Diabetes discovery & $15(9.2)$ & $12(2.4)$ & $<0.001$ \\
\hline Hyperglycaemia $>15 \mathrm{mmol} / \mathrm{L}$ with or without symptoms & $120(73.6)$ & $319(62.8)$ & 0.01 \\
\hline Diabetic foot & $17(10.4)$ & $143(28.1)$ & $<0.001$ \\
\hline Treatment of obesity & $9(5.5)$ & $31(6.1)$ & 0.78 \\
\hline Other & $2(1.2)$ & $3(0.6)$ & 0.60 \\
\hline \multicolumn{4}{|l|}{ Associated chronic diseases } \\
\hline Arterial hypertension & $54(33.1)$ & $326(64.2)$ & $<0.001$ \\
\hline Dyslipidaemia & $52(31.9)$ & $290(57.1)$ & $<0.001$ \\
\hline Cardiovascular diseases & $32(19.6)$ & $258(50.8)$ & $<0.001$ \\
\hline \multicolumn{4}{|l|}{ Chronic renal failure } \\
\hline $\mathrm{GFR}=30-59 \mathrm{ml} / \mathrm{min}$ & $20(12.3)$ & $95(18.7)$ & 0.06 \\
\hline $\mathrm{GFR}<30 \mathrm{ml} / \mathrm{min}$ & $8(4.9)$ & $62(12.2)$ & $<0.01$ \\
\hline Lung diseases & $23(14.1)$ & $94(18.50)$ & 0.19 \\
\hline Infectious diseases & $28(17.2)$ & $107(21.1)$ & 0.28 \\
\hline Obstructive sleep apnoea syndrome & $12(7.4)$ & $138(27.2)$ & $<0.001$ \\
\hline No. of chronic diseases* & $3(1.5-5)$ & $4(5-6)$ & $<0.001$ \\
\hline \multicolumn{4}{|l|}{ Type and time of admission } \\
\hline From emergency department & $33(20.3)$ & $57(11.2)$ & $<0.001$ \\
\hline Night or weekend & $17(10.4)$ & $30(5.9)$ & 0.049 \\
\hline Length of stay, days & $4(3-6)$ & $4(4-7)$ & 0.008 \\
\hline \multicolumn{4}{|l|}{ Number of medications* } \\
\hline At admission & $5(2-9)$ & $9(6-12)$ & $<0.001$ \\
\hline At discharge & $6(3-10)$ & $10(7-13)$ & $<0.001$ \\
\hline \multicolumn{4}{|l|}{ Medication errors } \\
\hline No. of participants with medication errors at admission & $35(21.5)$ & $113(22.2)$ & 0.84 \\
\hline $\begin{array}{l}\text { No. of participants with serious or very serious medication error at } \\
\text { admission }\end{array}$ & 14 of $35(40.0)$ & 38 of $113(33.6)$ & 0.49 \\
\hline No. of participants with medication errors at discharge & $14(9.0)$ & $59(12.2)$ & 0.28 \\
\hline $\begin{array}{l}\text { No. of participants with serious or very serious medication error at } \\
\text { discharge }\end{array}$ & 3 of $14(21.4)$ & 27 of $59(45.8)$ & 0.13 \\
\hline \multicolumn{4}{|l|}{ No. of medication errors per participant* } \\
\hline At admission & $1(1-2)$ & $1(1-2)$ & 0.44 \\
\hline At discharge & $1(1-1)$ & $1(1-1)$ & 0.82 \\
\hline \multicolumn{4}{|l|}{ Percentage of medication errors per treatment* } \\
\hline At admission & $16.7(12.5-26.8)$ & $12.5(9.0-20.0)$ & 0.02 \\
\hline At discharge & $11.1(9.9-12.9)$ & $9.1(7.4-13.4)$ & 0.15 \\
\hline
\end{tabular}

Values are given as $n(\%)$ unless indicated otherwise; values are median (interquartile range). Number of chronic diseases included Type 1 and 2 diabetes. Very serious medication error was defined as all errors that could lead to very serious or life-threatening consequences. Serious medication error was defined for errors that may cause harm or extend duration of hospital stay.

in people with Type 2 diabetes $(26.8 \%$ vs $41.5 \%$, $P<0.05)$. Medication errors involving added medications were more frequent in people with Type 1 diabetes $(17.1 \%$ vs $4.5 \%, P<0.001)$ and in $57.1 \%$ of the cases a diabetic drug was wrongly added. The potential severity of medication errors did not differ significantly between groups, either admission or discharge, with $37 \%$ serious or very serious errors overall.

\section{Risk factors of medication errors}

Results for the association between type of diabetes and the risk of medication errors or the risk of serious medication errors are shown in Fig. 1. In model 1, which was a crude model, the type of diabetes was not significantly associated with the risk of medication errors or serious medication errors. Adjustment for the number of lines of treatment (model 2) resulted in an increase in all ORs, corresponding to an increased risk in medication errors with Type 1 diabetes. Finally, further adjustment for age revealed an increased risk for Type 1 diabetes only at admission. So, for a given age and number of lines of treatment, people with Type 1 diabetes had an approximately twofold higher risk of medication errors (OR 1.72, 95\% CI 1.02-2.94) and serious medication errors (OR 2.17, 95\% CI 1.02-4.76), at admission. The effect of the number of lines of treatment in the prescription was highly significant $(P<0.001)$.

\section{Discussion}

The key finding of our study is that for a given number of treatments, people with Type 1 diabetes had an increased 


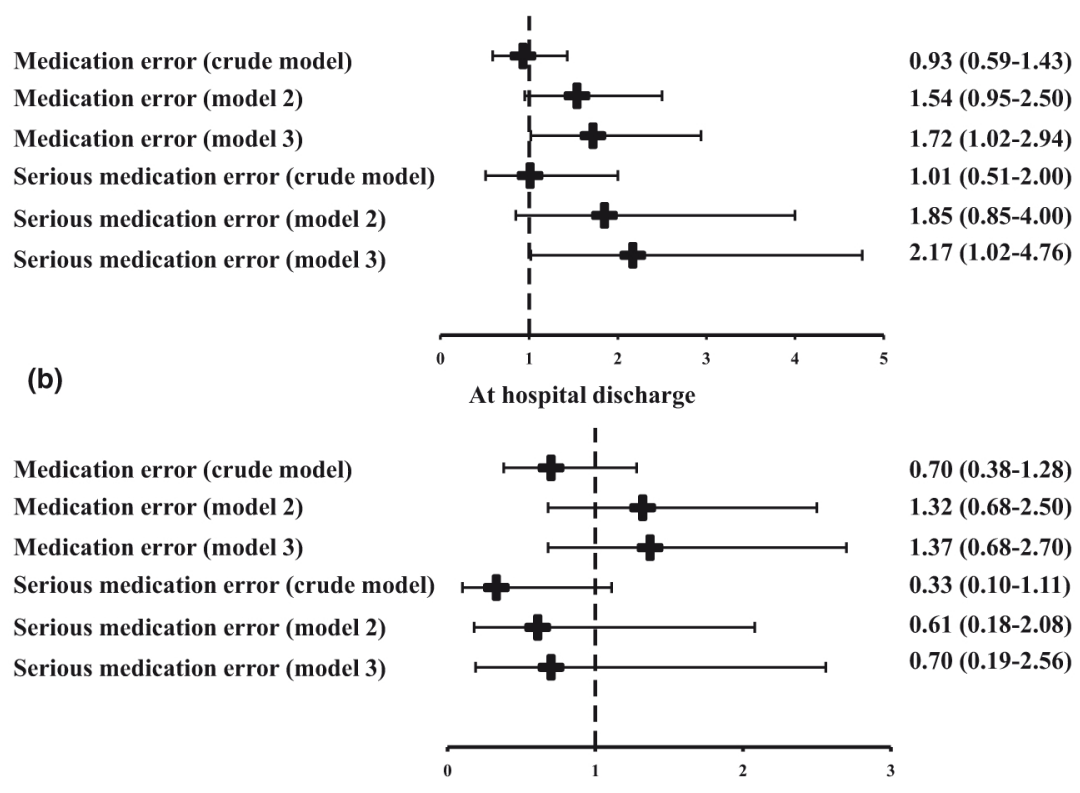

FIGURE 1 Odds ratios (ORs) of medication errors in Type 1 vs Type 2 diabetes at admission (a) and discharge (b): multivariable logistic regression analysis. Model 2 is adjusted for the number of lines of treatment. Model 3 is adjusted for the number of lines of treatment and age. Bars indicate $95 \%$ confidence intervals $(\mathrm{CI})$. Dotted line, null value $(\mathrm{OR}=1.0)$.

risk of medication errors and serious medication errors compared with those with Type 2 diabetes. Several hypotheses could explain this result. First, people with Type 1 diabetes were more often admitted as an emergency. Second, higher medication errors involving added medications and drugs used for diabetes management were observed in people with Type 1 than in those with Type 2 diabetes. Lastly, the percentage of medication errors per treatment was significantly higher in the Type 1 diabetes population at admission. Thus, the association of these results may explain the finding that those with Type 1 diabetes were more at risk of medication errors and serious medication errors at hospital admission.

These results are comparable with those of the National Diabetes Inpatient Audit of 2015 [16]. This audit showed that medication errors were significantly more frequent for hospitalized people with Type 1 diabetes $(48.1 \%)$ and Type 2 insulin-treated diabetes $(48.9 \%$ ) compared with those with Type 2 non-insulin-treated diabetes (29.7\%). Moreover, in this audit, the logistic regression analysis highlighted that non-insulin-treated hospitalized people admitted for nondiabetes medical reasons had a lower risk of a medication error $(\mathrm{OR}=0.77,95 \%$ CI $0.66-0.89)$. Lastly, elective admission was associated with a reduced risk of having mild or severe hypoglycaemic episodes, whereas insulin or sulphonylurea treatment at admission was associated with an increased risk. Therefore, the type (elective or non-elective) and reason (related or not to diabetes) for admission and diabetes treatment (insulin or not) are crucial variables that might explain the difference in terms of incidence and severity of medication errors depending on diabetes type.

Our study has some limitations, the main one being its observational design without any control arm and its monocentric nature, which might limit the generalizability of our results. Moreover, medication reconciliation programmes can prevent prescription errors, but they cannot prevent dispensing and administration errors, therefore precluding the evaluation of all types of medication errors.

In conclusion, our study highlighted that people with Type 1 diabetes had an approximately twofold higher risk of medication errors and serious medication errors at hospital admission compared with those with Type 2 diabetes. The interventions of clinical pharmacists should focus on at-risk populations such as poly-medicated people, but also other high-risk groups, such as those with Type 1 diabetes.

\section{Funding sources}

None.

\section{Competing interests}

None declared.

\section{Acknowledgements}

The authors would like to thank Oceane Abraham and Laura di-Trapani for assistance during this study. 


\section{References}

1 Institute of Medicine. Preventing Medication Errors. Washington, DC: The National Academies Press, 2006. Available at https://doi. org/10.17226/11623 Last accessed 30 August 2017.

2 World Health Organization. The High 5s Project. Interim Report. 2013. Available at http://www.who.int/patientsafety/topics/high-5s/ en Last accessed 30 August 2017.

3 The Joint Commission. Hospital: 2017 National Patient Safety Goals. 2017. Available at https://www.jointcommission.org/hap_ 2017_npsgs/ Last accessed 30 August 2017.

4 Rose AJ, Fischer SH, Paasche-Orlow MK. Beyond medication reconciliation: the correct medication list. JAMA 2017; 317: 20572058.

5 Mekonnen AB, McLachlan AJ, Brien JE. Pharmacy-led medication reconciliation programmes at hospital transitions: a systematic review and meta-analysis. J Clin Pharm Ther 2016; 41: 128-144.

6 Belda-Rustarazo S, Cantero-Hinojosa J, Salmeron-Garcia A, Gonzalez-Garcia L, Cabeza-Barrera J, Galvez J. Medication reconciliation at admission and discharge: an analysis of prevalence and associated risk factors. Int J Clin Pract 2015; 69: 1268-1274.

7 Feldman LS, Costa LL, Feroli ERJr, Nelson T, Poe SS, Frick KD et al. Nurse-pharmacist collaboration on medication reconciliation prevents potential harm. J Hosp Med 2012; 7: 396-401.

8 Gleason KM, McDaniel MR, Feinglass J, Baker DW, Lindquist L, Liss D et al. Results of the Medications at Transitions and Clinical Handoffs (MATCH) study: an analysis of medication reconciliation errors and risk factors at hospital admission. J Gen Intern Med 2010; 25: 441-447.

9 Pippins JR, Gandhi TK, Hamann C, Ndumele CD, Labonville SA, Diedrichsen EK et al. Classifying and predicting errors of inpatient medication reconciliation. J Gen Intern Med 2008; 23: 14141422.

10 Vira T, Colquhoun M, Etchells E. Reconcilable differences: correcting medication errors at hospital admission and discharge. Qual Saf Health Care 2006; 15: 122-126.

11 Magalhaes GF, Santos GN, Rosa MB, Noblat Lde A. Medication reconciliation in patients hospitalized in a cardiology unit. PLoS One 2014; 9: e115491.

12 Salanitro AH, Osborn CY, Schnipper JL, Roumie CL, Labonville S, Johnson DC et al. Effect of patient- and medication-related factors on inpatient medication reconciliation errors. J Gen Intern Med 2012; 27: 924-932.

13 Hellstrom LM, Bondesson A, Hoglund P, Eriksson T. Errors in medication history at hospital admission: prevalence and predicting factors. BMC Clin Pharmacol 2012; 12: 9.

14 van den Bemt PM, van der Schrieck-Loos EM, van der Linden C, Theeuwes AM, Pol AG. Effect of medication reconciliation on unintentional medication discrepancies in acute hospital admissions of elderly adults: a multicenter study. J Am Geriatr Soc 2013; 61: 1262-1268.

15 Breuker C, Abraham O, di Trapanie L, Mura T, Macioce V, Boegner $\mathrm{C}$ et al. Patients with diabetes are at high risk of serious medication errors at hospital: interest of clinical pharmacist intervention to improve healthcare. Eur J Intern Med 2017; 38: $38-45$.

16 The Health and Social Care Information Centre. National Diabetes Inpatient Audit 2015. Available at http://content.digital.nhs.uk/sea rchcatalogue productid $=20443 \& \mathrm{q}=$ national + diabetes + inpatient $+\mathrm{a}$ udit $\&$ sort $=$ Relevance $\&$ size $=10 \&$ page $=1 \#$ top Last accessed 30 August 2017. 